\title{
Interactive website with systems analysis environment for prefeasibility studies of small scale water and power production units integrating renewable energy
}

\author{
Djamal Boudieb, Kamal Mohammedi, Abdelkader Bouziane, Youcef Smaili
}

MESOteam, LEMI, M. Bougara University Boumerdes, Algeria

Email address:

djamelboudieb@yahoo.fr(D. Boudieb)

\section{To cite this article:}

Djamal Boudieb, Kamal Mohammedi, Abdelkader Bouziane, Youcef Smaili. Interactive Website with Systems Analysis Environment for Prefeasibility Studies of Small Scale Water and Power Production Units Integrating Renewable Energy. Journal of Water Resources and Ocean Science. Vol. 2, No. 5, 2013, pp. 62-67. doi: 10.11648/j.wros.20130205.12

\begin{abstract}
This paper focuses on RESYSproDESAL systems analysis environment (SAE) for the prediction of technical, economic and ecological performance of water and power point systems including desalination (e.g. membrane and thermal processes), renewable energy sources for power (e.g. wind energy and photovoltaics) and conventional power supply (e.g. Diesel GenSet).This tool was developed within EU FP6 projects in cooperation between EU-MENA countries. The SAE is applied to a small scale container system for $10 \mathrm{~m}^{3} /$ day seawater reverse osmosis desalination powered from Diesel and photovoltaics. Starting from a reference design case three alternative configurations and size are developed and analysed for comparison. The results show a considerable potential for economic improvement of the plant concept, bringing the project closer to affordability for the target population: Optimized Diesel and battery sizes reduce levelised water cost by about $15 \%$. Up-sizing the whole system from 10 to $50 \mathrm{~m}^{3} / \mathrm{d}$ and power recovery reduce specific power consumption by about $45 \%$ and integration of water production with village power supply may meet user needs better and increase reliability of back-up.
\end{abstract}

Keywords: Desalination, Renewable Energy, Co-Generation, Performance, Systems Analysis

\section{Introduction}

Most Middle East and Northern Africa (MENA) countries are facing growing problems of water supply. Impressive efforts are dedicated to the implementation of large scale equipment with well proven cost-effective technologies for central sea water desalination at coastal sites or brackish water desalination near inland cities. However there are many technically neglected places remote from the countries' centres of water and power production. Typically such settlements of few hundred people with no clean underground water depend from long distance transport of water by truck with high risks due to limited reliability of driver, vehicle and fuel supply as well as hygienic deficiencies of equipment. The true cost of such methods of supply is often not evaluated by the responsible authorities. If grid power connection is not at reach the village may have a simultaneous problem of water and power supply. The inhabitants of such places deserve safer and cost-effective solutions for satisfaction of their needs for an acceptable standard of living. Water and power production should be implemented on site employing appropriate technologies and making best use of local resources of energy, material and labour. Therefore European experts in small and medium scale desalination and hybrid power generation from conventional and renewable energy sources are developing engineering methods for Integrated Water and Power Point (IWPP) systems, characterised by flexible design, fast implementation, energy efficiency and low emissions. A consortium composed by ZSW (Germany), NERC (Jordan), MESOteam/UMBB (Algeria) and SimTech (Austria)has been involved in the development of the systems analysis environment (SAE) RESYSproDESAL for the prediction of technical, economic and ecological performance of water and power point systems including desalination and water treatment (e.g. membrane and thermal processes), renewable energy sources for power (e.g. wind energy conversion and photovoltaic power generation) and conventional power generator (e.g. Diesel GenSet) Mohammedi, 2006. 
The process simulation within this tool is done with the commercial software IPSEpro from company SimTech in Austria. The standard library of this programmewas extended with special models for desalination equipment and components for conversion of renewable energy.

The challenge of such systems analysis and engineering stems from the necessarily integrative character for the solutions: Usually only simultaneous water and power production and hybrid utilisation of conventional and renewable energy sources make reliable and cost-effective solutions feasible. The integrative character of the engineering approach is recognised from. Fig. 2, showing a typical case of integrated water and power production by a sea water reverse osmosis (SWRO) desalination plant powered from hybrid fossil/renewable energy conversion from Diesel engine and photovoltaics (PV).

There are two subsystems in this example:

- The water treatment system including sea water intake (or well), pre-treatment tank and dosing of chemicals, high pressure pump, pressure vessels for reverse osmosis, post-treatment and storage of permeate, disposal of concentrate.

- The power supply system including PV generator, Diesel GenSet, electric energy storage (accumulator), inverters $\mathrm{DC} / \mathrm{AC}$ and reverse, power busbar with load management control system. The busbar may be equipped with connections for another power source, e.g. Wind energy Converter (WEC), and for export of power into a local (village) power grid.

\section{Modelling, Simulation and Analysis Environment}

The simulation and optimisation of the the $48 \mathrm{~m}^{3} /$ day brackish water Reverse Osmosis small scale desalination unit powered from PV and Diesel generatoris done with RESYSproDESAL tool under IPSEpro System Analysis EnvironmentRheinländer,2003. RESYSproDESAL tool for simulation can help design and optimize water-renewable production systems. The standard library of this software was extended using MDK toolkit with Resysprospecfic models for desalination equipment and components for conversion of renewable energy.The challenge of such systems analysis and engineering stems from the necessarily integrative character for the solutions: Simultaneous water and power production and hybrid utilisation of conventional and renewable energy sources make reliable and cost-effective solutions feasible.

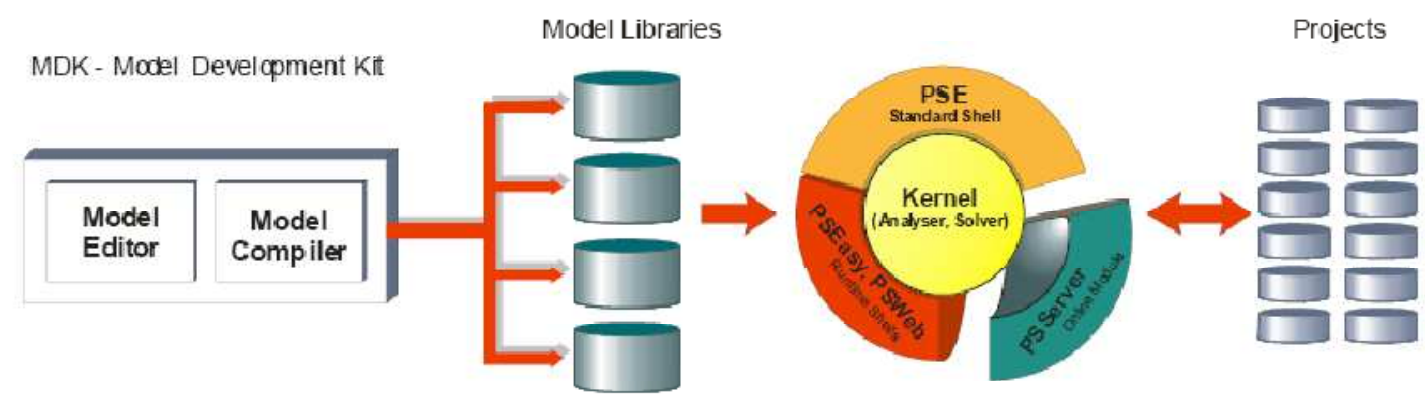

Figure 1: IPSEpro architecture

\section{Case Studies in Algeria}

\subsection{Case 1: Azeffoun}

Located on the mediteranean coast, $150 \mathrm{~km}$ east of Algiers and $20 \mathrm{~km}$ east of Azzefoun small village, Asseklu site is in the heart of the ZET (Zone d'ExpansionTouristique) nearby the Guraya National Park. With an annual average of wind velocity at $10 \mathrm{~m}$ height of $8.4 \mathrm{~m} / \mathrm{s}$, the site should be suitable for wind energy conversion.

The main indicative data of Azzefoun (Asseklu) site case study are summarized below:

Coordinates: 36.9 N,4.7 E, time zone 1

Climate:Mediterranean

Conventional Energy:none

Elevation: $30 \mathrm{~m}$

Pumping head including height of the tank: $10 \mathrm{~m}$

Raw water: sea water

\section{WaterSalinty: 40000 ppm TDS}

Irradiation:4500 Wh/day min., $5400 \mathrm{Wh} /$ day max.

Population are semi scattered. Houses may have around $60 \mathrm{~m}$ distance from each others. Estimated number of population is around 200. Daily demand for potable water is around $40 \mathrm{~m}^{3} /$ day.

\subsection{SWRO Desalination}

The operation of the system shall aim at a daily production of $10 \mathrm{~m}^{3}$ of potable water. A performance simulation of the integrated $\mathrm{RO}+\mathrm{PV}+$ Dieselwas done with the RESYSproDESALtool for systems analysis. The process simulation in this tool is done with the commercial software IPSEpro extended with special models for desalination equipment and components for conversion of renewable energyKershman, 2002. The process scheme for the integrated $\mathrm{RO}+\mathrm{PV}+$ Diesel system is shown in Fig. 1. The scheme is designed for more general applications 
including another renewable power source (e.g. wind energy conversion) and power supply to a village grid. By setting zero power flows for these connections they are excluded from process simulation.

The simulation of the RO process was done assuming the same set of pressure vessels and membranes as reported: 2 streams with 2 vessels each and 2 membranes type SW302540 from FILMTEC per vessel. However the (water) recovery rate calculated here is $49 \%$ against $40 \%$ reported, though in both cases a fouling factor of 0.85 was assumed.

\section{Design Results}

Energy

\begin{tabular}{|c|c|c|}
\hline Description & value & Unit \\
\hline total power requested by SWRO at nominal operation conditions & 6.8 & $\mathrm{~kW}$ \\
\hline specific energy consumption for SWRO process (all auxil. included) & 3.07 & $\mathrm{kWh} / \mathrm{m}^{3}$ \\
\hline power generated by PV system (output from inverter for default op.) & 12.3 & $\mathrm{~kW}$ \\
\hline ratio of annual RE supply to demand from process & 0.4606 & ---- \\
\hline annual consumption of fuel for Diesel GenSet & 104198 & $\mathrm{~kg} / \mathrm{a}$ \\
\hline \multicolumn{3}{|l|}{ annual energy supplied or consumed } \\
\hline to desalination process and auxiliary loads & 59706 & $\mathrm{kWh} / \mathrm{a}$ \\
\hline from RE sources via busbar to grid & 2757 & $\mathrm{kWh} / \mathrm{a}$ \\
\hline from RE sources to busbar & 27499 & $\mathrm{kWh} / \mathrm{a}$ \\
\hline from village to grid connection node & 0 & $\mathrm{kWh} / \mathrm{a}$ \\
\hline from grid connection node to village & 249040 & $\mathrm{kWh} / \mathrm{a}$ \\
\hline from Diesel to grid connection node & 281247 & \\
\hline
\end{tabular}

Cost

\begin{tabular}{|c|c|c|}
\hline Description & value & Unit \\
\hline \multicolumn{3}{|l|}{ Present Worth } \\
\hline investment (total plant) & 186252 & $€$ \\
\hline investment for desalination system & 43593 & $€$ \\
\hline fixed O\&M costs (total plant) & 257998 & $€$ \\
\hline fixed O\&M costs for desalination system & 184571 & $€$ \\
\hline variale $O \& M$ costs (total plant) & 42294 & $€$ \\
\hline variable $\mathrm{O} \& \mathrm{M}$ costs for desalination system & 38632 & $€$ \\
\hline replacement costs (total plant) & 23854 & $€$ \\
\hline replacement costs for desalination system & 10692 & $€$ \\
\hline cost of fuel consumed on site & 597571 & $€$ \\
\hline water sold & 437451 & $€$ \\
\hline electricity sold & 667271 & $€$ \\
\hline net (NPW) & -3247 & $€$ \\
\hline levelised electricity cost (LEC) & 0.2345 & $€ / \mathrm{kWh}$ \\
\hline levelised water cost (LWC) & 2.182 & $€ / \mathrm{m}^{3}$ \\
\hline period for payback of investment from discounted net cash flow & 20.4 & $\mathrm{a}$ \\
\hline
\end{tabular}

Ecology

\begin{tabular}{lrr}
\hline Description & Unit & value \\
\hline annual emission of CO2 from Diesel GenSet operation & 343615 \\
specific CO2 emission from local electricity production & $\mathrm{kg} / \mathrm{a}$ & 1.113 \\
\hline
\end{tabular}




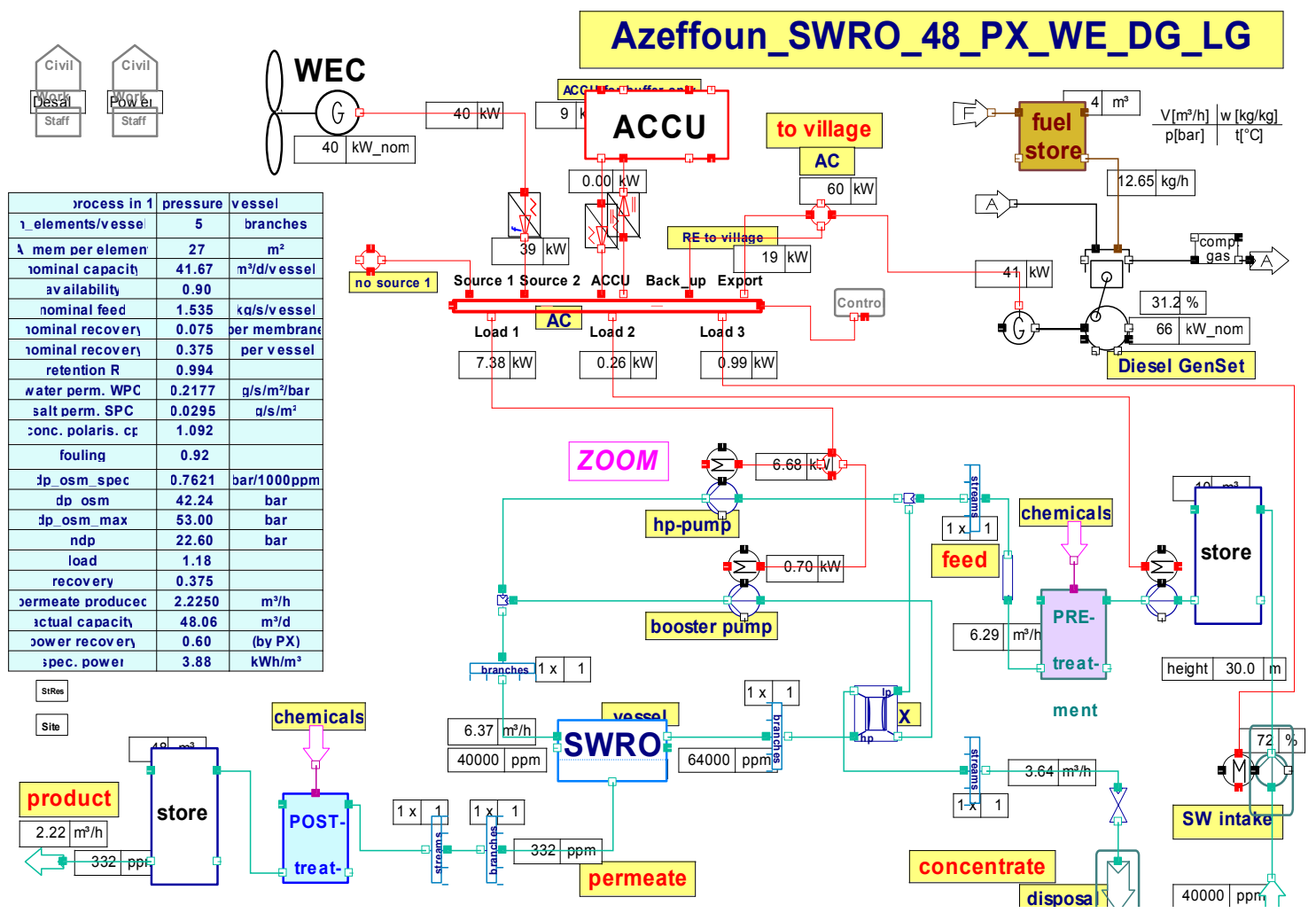

Figure 2 : Desalination process flowsheet

\subsection{Case2: Hassikhebbi}

Coordinates: 29.2 N,5.4 W, time zone 1

Elevation: $90 \mathrm{~m}$

Pumping head including height of the tank: $10 \mathrm{~m}$

Water Salinity: 2000 ppm

Populations are semi scattered. Houses may have around $40 \mathrm{~m}$ distance from each others, but this is not a problem since there is an already water network existing from the well to the houses. Estimated number of population is around 600. Daily demand for potable water is around 40 $\mathrm{m}^{3} /$ day

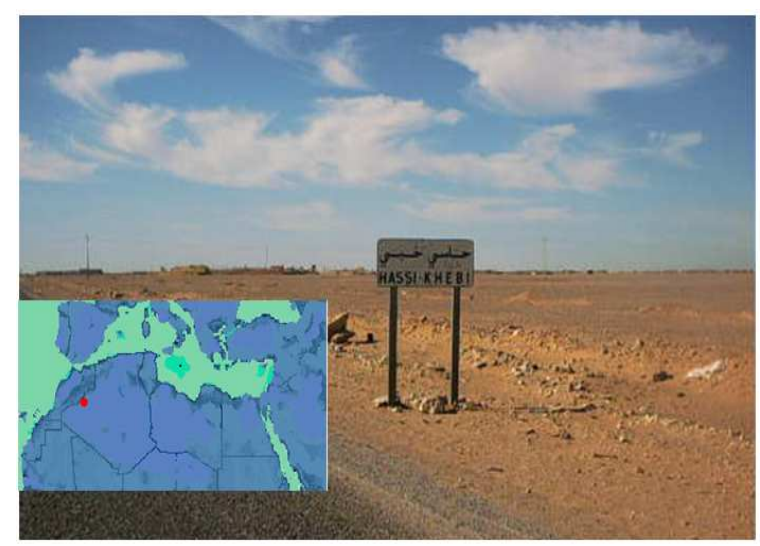

Figure 4. Hassi Khebbi Location and view

\subsection{BWRO Desalination}

The design of the $48 \mathrm{~m}^{3} / \mathrm{d}$ brackish water RO powered from PV and Diesel generator with connection to local grid assumes demand for simultaneous supply of water and power to a village Boudieb, 2012. The system is composed from 3 subsystems:

- $\quad$ BWRO brackish water desalination

- PV modules power generation

- Diesel generator set

Energy integration of the subsystems is controlled by a power busbar with load management.

The desalination subsystem includes:

- BWRO water treatment with parallel RO vessels (branches) in parallel streams

- High pressure feed pump in every stream

- Chemical pre- and post-treatment

- Raw water and product storage tanks

- Brackish water intake

- Concentrate disposal

- $\quad \mathrm{AC}$ electric motors for all pumps

- Headers for splitting and mixing of streams and branches 


\section{Design Results}

Cost

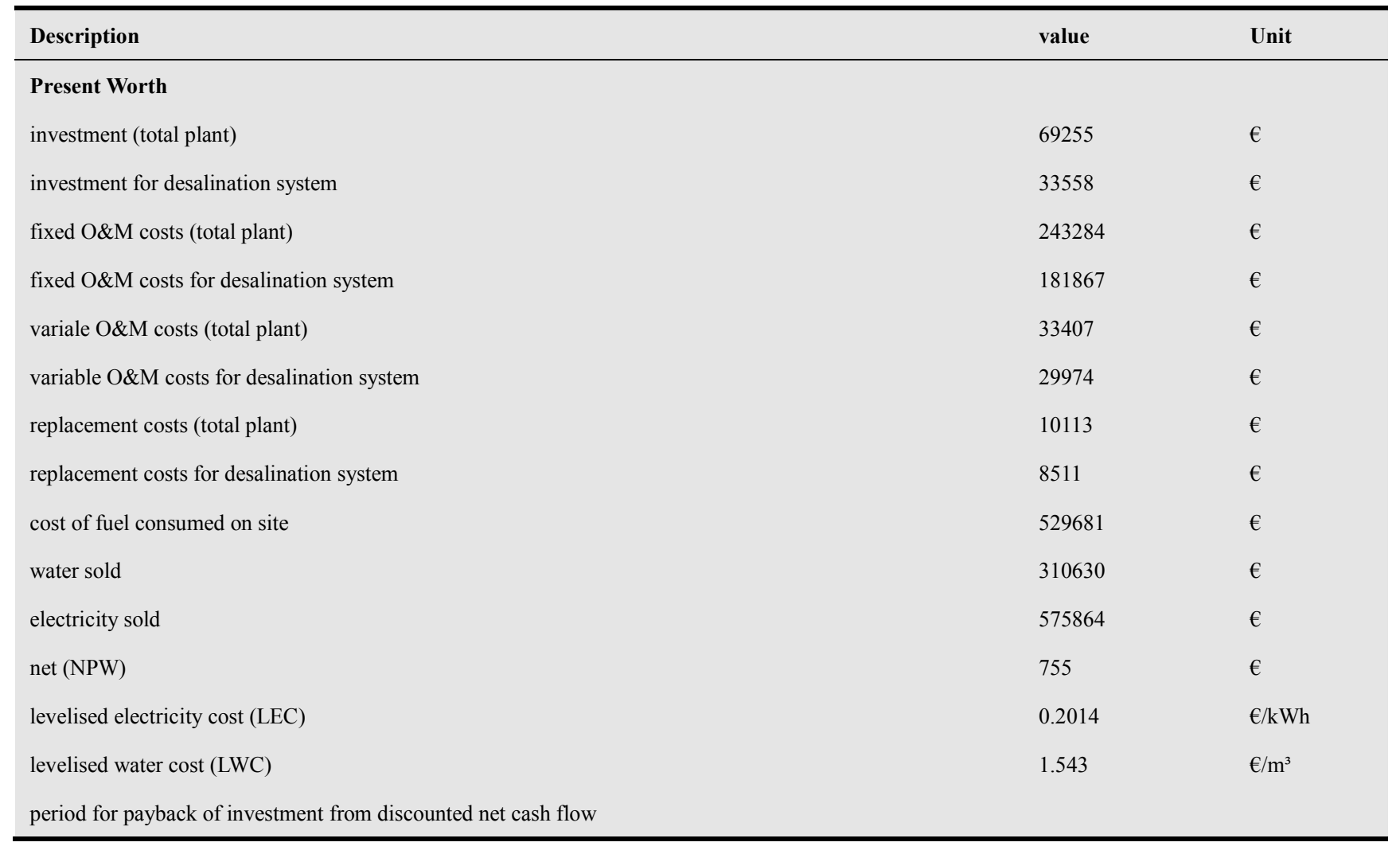

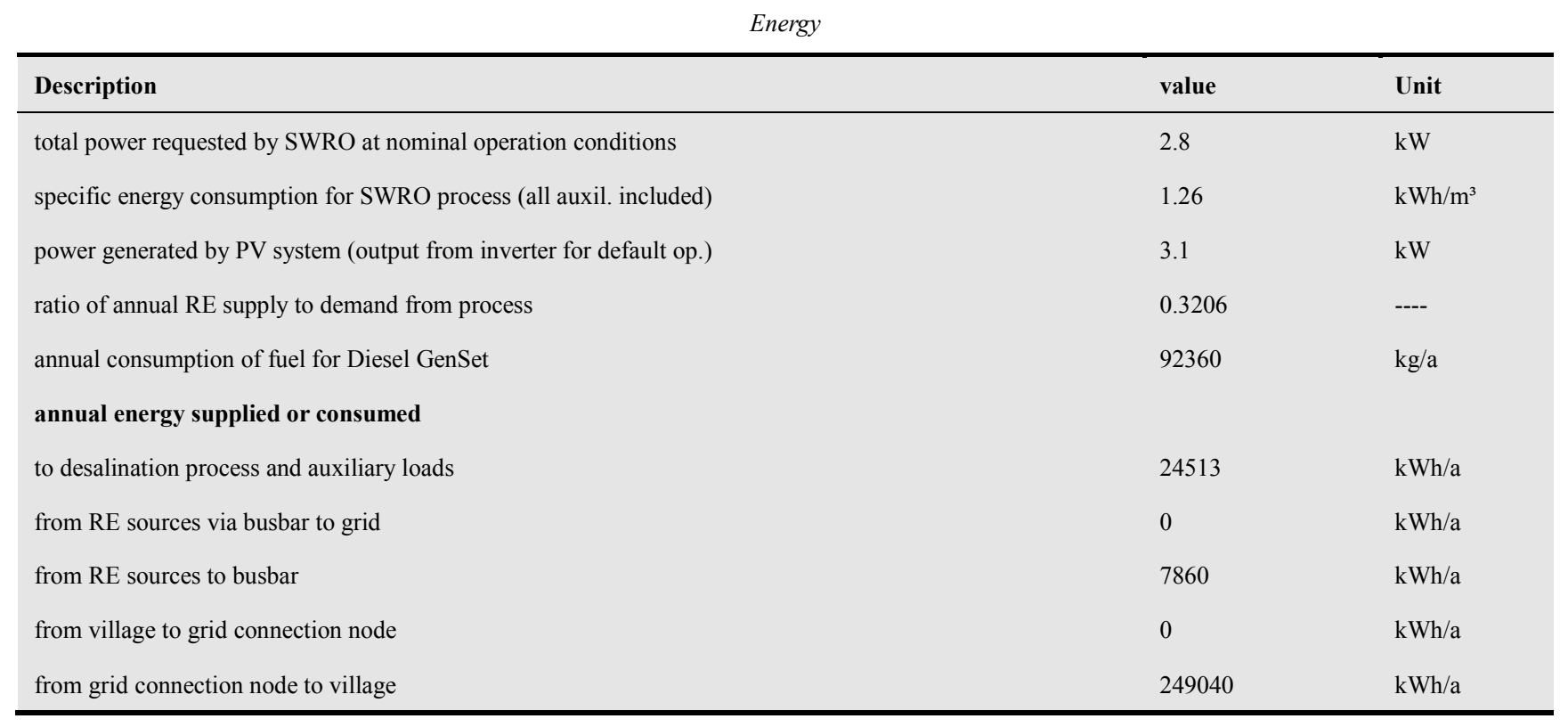

Ecology

\begin{tabular}{lcc}
\hline Description & value & Unit \\
\hline annual emission of CO2 from Diesel GenSet operation & 304577 & $\mathrm{~kg} / \mathrm{a}$ \\
specific CO2 emission from local electricity production & 1.113 & $\mathrm{~kg} / \mathrm{kWh}$ \\
\hline
\end{tabular}




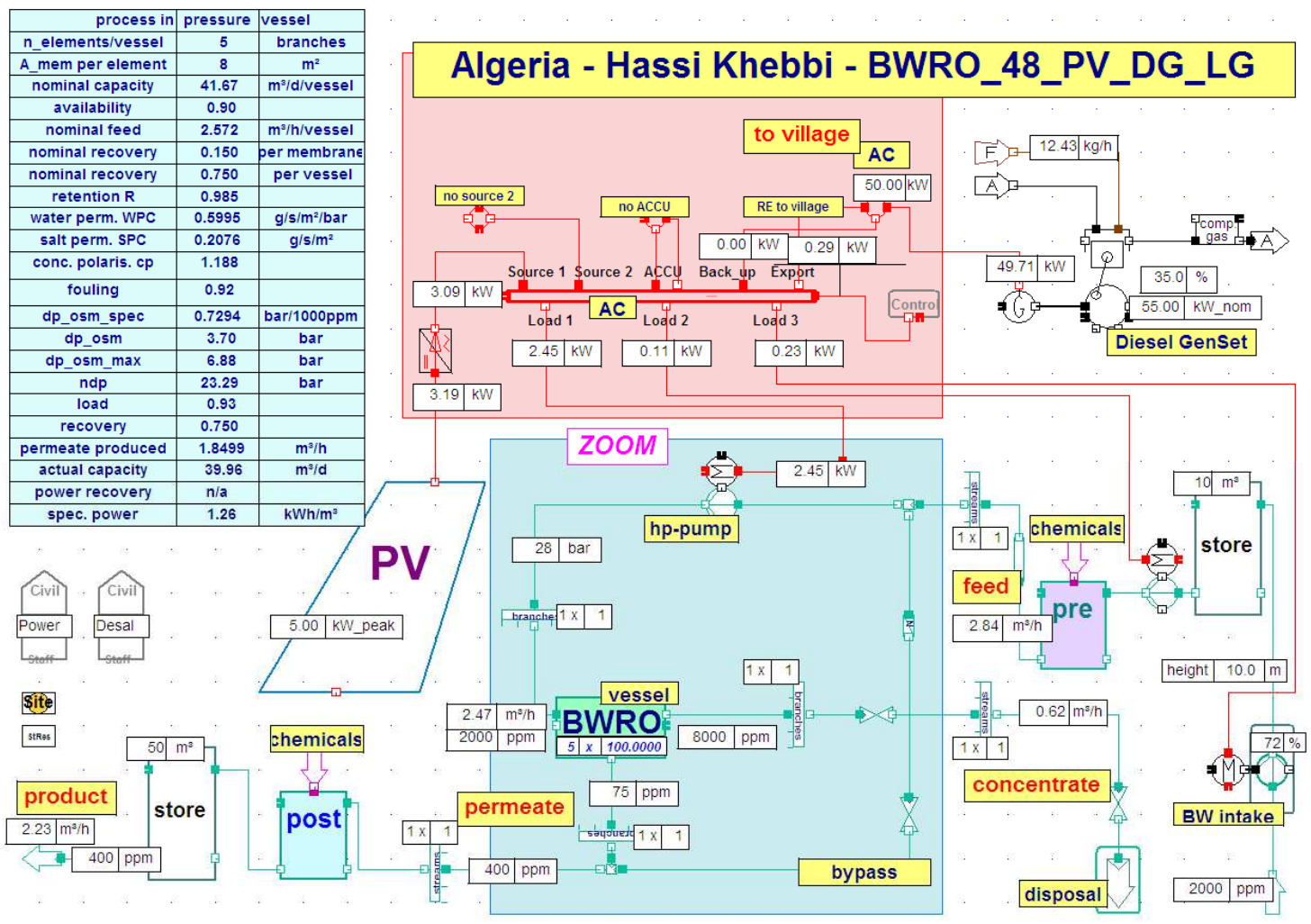

Figure 5. Hassi Khebbi case study Ipsepro FlowSheet

\section{Conclusion}

In this paper, we presented two case studies with SWRO and BWRO desalination respectively. The results of simulations under IPSEpro environment with a case study concerned with a $48 \mathrm{~m}^{3} /$ day seawater reverse osmosis (SWRO) desalination in Algeria on the east Mediterranean coastwith up to $60 \mathrm{~kW}$ additional power supply to the consumers of the water.The desalination subsystem is large enough to include energy recovery by pressure exchanger. The technical performance simulation predicts more than $80 \%$ fraction of the wind power contribution to the annual demand. The results show a potential for economic improvement of the system design reducing the expected levelised water (production) cost from the economic analysis under 2 Euros $/ \mathrm{m}^{3}$. Naturally, this case study can be extended to other south Mediterranean countries sharing the same conditions.

The Hassi-Khebbi Brackish water Reverse osmosis desalination plant aims a daily production of $48 \mathrm{~m}^{3}$ of potable water. the integrated $\mathrm{RO}+\mathrm{WE}+$ Diesel simulation was done with the RESYSproDESAL systems analysis tool. The process simulation in this tool is done under IPSEpro extended with special models for desalination equipments and components for conversion of renewable energy. The scheme is designed for more general applications including another renewable power source (e.g. wind energy conversion) and power supply to a village grid. By setting zero power flows for these connections they are excluded from process simulation. With a solar fraction of less than $1 / 3$ of the annual electricity supplied to the BWRO process the originally projected hybrid system more likely is a BWRO Diesel-System with PV for back-up than the opposite.

\section{References}

[1] Boudieb, D, Mohammedi, K, Sadi, A, Smaili,Y," Analysis and optimization of a small scale bwro desalination plant integrating renewable energy", International Conference on Nuclear \& Renewable Energy Resources, Istanbul, Turkey, 20-23 May 2012

[2] Kershman, S.A., Rheinländer, J., Gabler, H.: Seawater reverse osmosis powered from renewable energy sources hybrid wind/photovoltaic/grid power supply for small-scale desalination in Libya,. Desalination 153 (2002) pp. 17-23.

[3] Mohammedi,K., Rheinländer, J., Sadi, A.,: Performance Performance Analysis of De-central Water and Power Production by BWRO Integrating PV Solar Energy.Eurosun2006, Glasgow UK, June 2006.

[4] Rheinländer, J., Perz, E., Goebel, O., "Performance simulation of integrated water and power systems - software tools IPSEpro and RESYSpro for technical, economic and ecological analysis", European Conference on Desalination and Environment: Fresh Water for All, Malta, 4-8 May 2003. 